\title{
Los juicios paralelos en el proceso penal: tratamiento mediático del 'caso bretón'
}

\author{
Parallel trials in criminal proceedings: media coverage of the \\ 'Breton case'
}

\author{
María SÁNCHEZ MONCADA \\ Universidad Carlos III de Madrid (UC3M) \\ moncadasanchez.m@gmail.com \\ María VEIGA FRANCO. \\ Universidad Carlos III de Madrid (UC3M) \\ mariaveifra@gmail.com
}

Recibido: 20 de junio de 2015 Aceptado y Publicado: 13 de julio de 2015

\begin{abstract}
Resumen
Los medios de comunicación desempeñan un papel fundamental en la consecución del principio de publicidad del procedimiento penal, al permitir que los juicios sean conocidos más allá del círculo de los implicados en ellos. El problema surge cuando, al informar sobre asuntos judiciales, los medios inducen a la opinión pública a generar un veredicto anticipado de culpabilidad de una persona, menoscabando gravemente sus derechos fundamentales a la defensa, al honor, a la propia imagen y a la presunción de inocencia. Mediante esta investigación se pretende analizar el fenómeno de los juicios paralelos a través del tratamiento mediático del caso Bretón, partiendo de la hipótesis de que la televisión contribuyó a generar un juicio paralelo al margen de los tribunales y la investigación jurídico-policial. Para ello, se ha examinado la cobertura del caso en dos programas de la televisión española como son La Mañana de la 1 (de Televisión Española) y El Programa de AR (de Telecinco). Los resultados corroboran que ambos programas construyeron un relato del suceso que contribuyó a culpabilizar al acusado, José Bretón, con carácter previo al dictado de la sentencia judicial.
\end{abstract}

\section{Abstract}

The media carries out a very important role in the attainment of the penal procedure publicity principle, permitting the judges to be known in circles far away from those in which they are involved. The problem arises when, whilst trying to inform about 
judicial aspects, the media induces the public opinion to generate a verdict anticipating the guilty verdict, harming their fundamental rights to defence, honour, and the right to self image and presumption of innocence. With this investigation we pretend to analyse the phenomenon of parallel trials through the media treatment of the "Bretón case", starting from the hypothesis that the TV contributed to generate a parallel trial outside of the court and the police and justice investigations. For this, we have examined the coverage of the case in two programs of Spanish television: $\mathrm{La}$ Mañana de la 1 (from Televisión Española) and El Programa de AR (from Telecinco). The results confirm that both programmes constructed a story about the event which contributed to lay the blame on the accused, José Bretón, with a previous nature to the dictates of the judicial sentence.

Palabras clave: Caso Bretón; información; juicio paralelo; presunción de inocencia; proceso judicial; televisión.

Keywords: Breton case; information; parallel trial; presumption of innocence; television; trial.

\section{1.- Marco teórico}

En los últimos años, la información relacionada con los procesos judiciales, especialmente en el ámbito penal, ha cobrado un importante interés informativo. La trascendencia pública que poseen determinados juicios justifica su amplio seguimiento por parte de los medios de comunicación, que ofrecen una información exhaustiva sobre su desarrollo (Orenses, 2014:121). La cobertura mediática se encuentra íntimamente ligada al principio de publicidad del proceso judicial, consagrado en el artículo 120 de la Constitución Española (CE). Dicho precepto establece que las actuaciones judiciales serán públicas, a excepción de las que expresamente prevean las leyes de procedimiento en aras a salvaguardar los intereses de las partes o los fines del proceso.

La publicidad de los procedimientos constituye una garantía de los derechos naturales, inalienables y sagrados del hombre frente al arbitrio judicial y las eventuales manipulaciones gubernamentales en la constitución y funcionamiento de los tribunales de justicia. Asimismo, configura el cauce a través del cual la sociedad ejerce el control sobre el funcionamiento de la Administración de Justicia (Barrero, 2001: 51). Teniendo presentes estas consideraciones, no cabe duda de la importante labor que desempeñan los medios de comunicación en la consecución de este mandato constitucional, función que ha reconocido el propio Tribunal Constitucional al declarar que "el principio de publicidad de los juicios [...] implica 
que estos sean conocidos más allá del círculo de los presentes en los mismos, pudiendo tener una proyección general, que únicamente puede hacerse efectiva con la asistencia de medios de comunicación social"1.

El ejercicio de este derecho a la información judicial debe efectuarse con especial cautela por parte de los periodistas, puesto que un inadecuado tratamiento informativo puede conculcar derechos fundamentales como el honor, la intimidad, la propia imagen, la presunción de inocencia o el derecho a un juicio justo con todas las garantías. Los riesgos se incrementan notablemente cuando nos referimos a medios de comunicación de masas como la prensa, la radio o la televisión. Algunos factores que contribuyen a hacer de los medios audiovisuales los más propensos a vulnerar derechos y bienes jurídicos dignos de protección son: la rapidez con la que hay que elaborar los contenidos y la dificultad de controlar las opiniones vertidas por los tertulianos en los programas en directo (Orenses, 2014: 122).

La situación se complica aún más cuando, ante determinados acontecimientos capaces de generar una gran conmoción pública, la información deja de ser materia exclusiva de los informativos y empieza a difundirse a través de otro tipo de formatos. Se trata de los nuevos programas de infoentretenimiento, que hibridan información y entretenimiento en un mismo espacio televisivo, con el objetivo de resultar atractivos para la audiencia, "que sigue siendo la fuente principal de ingresos de televisiones públicas y privadas dentro de un panorama altamente competitivo" (Bustamante, 1991).

Esta tendencia de los medios a presentar la información como espectáculo es lo que se conoce como infotainment -infoentretenimiento- (Thomas, 1990), fenómeno que ha dado lugar a una nueva noción de noticia, que conjuga elementos de humor y de tragedia y confunde lo nuevo, lo conflictivo o lo espectacular con lo importante. Además, suele ser un elemento común en este tipo de informaciones la constante apelación a los sentimientos, otorgando primacía a lo emocional por encima de lo racional (García Avilés, 2007: 51). En definitiva, se trata de lo que algunos han denominado «las otras noticias» (Langer 1998: 15) o «periodismo tabloide» (Sparks y Tulloch, 2000: 10), en el que los temas triviales sobre sucesos, accidentes, interés humano, entretenimiento y curiosidades desvían la atención sobre asuntos más relevantes. Los temas en este tipo de programas se banalizan y se genera el caldo de cultivo perfecto para la celebración de los denominados "juicios paralelos".

Los juicios paralelos hacen referencia a asuntos pendientes en los juzgados a los que los medios de comunicación someten a comentarios, valoraciones, 
apreciaciones y opiniones diversas con virtualidad suficiente para crear opinión pública acerca del hecho que será enjuiciado en un futuro (Juanes, 2007: 63). Esto puede tener incidencia tanto en la persona implicada en el proceso como en el devenir del procedimiento judicial. En primer lugar, la celebración de juicios paralelos puede causar daños de difícil o imposible reparación para el imputado. En segundo lugar, pueden perturbar la investigación, influir en la imparcialidad del Tribunal e, incluso, presionar a los jueces para que fallen de una determinada manera (Rodríguez Fernández, 2012: 1).

En este sentido, cabe recordar el histórico 'caso Alcásser', que conmocionó a la sociedad española en 1992 y mostró a la ciudadanía los excesos en que ciertos medios de comunicación -audiovisuales especialmente- incurrían en su presunto afán informativo (Macía y Galván 2012: 366), donde la tónica general fue el recurso sensacionalismo. En la misma línea, se encuentran los casos de Rocío Wanninkhof (1999), Marta del Castillo (2009) o, más recientemente, el de Asunta Basterra (2013), a cuya cobertura los medios de comunicación de masas han dedicado numerosas páginas y minutos. Todos estos sucesos se erigen como principales exponentes de esta problemática, donde el relato audiovisual traspasa la frontera de la mera información ajustada a los hechos y la opinión, y los juicios de valor infundados pasan a desempeñar el papel protagonista.

Así las cosas, el objetivo de la presente investigación es analizar el fenómeno de los juicios paralelos a través de un caso paradigmático como el de José Bretón. Un suceso en el que las víctimas fueron dos niños cordobeses, Ruth y José, y cuyo seguimiento ha ocupado numerosas horas de televisión, desde el inicio hasta la sentencia definitiva, dictada casi dos años después.

El 8 de octubre de 2011 en la provincia de Córdoba, desaparecen los menores Ruth (de 6 años) y José (de 2 años). En ese momento, los pequeños se encontraban bajo la tutela paterna, debido a que el matrimonio estaba en trámites de separación y ese fin de semana le tocaba al padre quedarse con los niños. José Bretón, progenitor de los desaparecidos, pronto acudió a comisaria a presentar una denuncia, alegando que, por despiste, había perdido de vista a sus hijos en el parque Cruz Conde (Córdoba). Desde el primer momento, las sospechas se centraron en la figura paterna, quien fue detenido por la policía diez días más tarde, debido a las contradicciones y lagunas que presentaba su relato acerca de la desaparición de los menores. Tras pasar a disposición judicial, el magistrado instructor decreta su ingreso en prisión provisional aduciendo que hay "indicios razonables de criminalidad"2. 
Los restos óseos hallados en la finca de los abuelos paternos y los estudios contradictorios de dos forenses sobre la naturaleza de aquellos huesos dieron un vuelco a la investigación y propiciaron un agitado debate en los medios de comunicación. Los programas de televisión dedicaron amplios espacios a la cobertura del caso: reportajes, conexiones en directo desde los principales escenarios del suceso, entrevistas a allegados de la familia y debates en plató. La mayoría, encaminados a enjuiciar y especular sin ningún tipo de pruebas al respecto, lo que en último término comporta el tratamiento banalizado del caso y que apela a la emoción por encima de los argumentos racionales, algo que puede resultar perjudicial para el transcurso de la investigación.

El 22 de julio de 2013, la Audiencia Provincial de Córdoba dicta sentencia por la que un jurado popular condena a José Bretón como autor de dos delitos de asesinato, con agravante de parentesco, a la pena de cuarenta años de prisión, con la accesoria de inhabilitación absoluta durante el tiempo de vigencia de la condena ${ }^{3}$. A la vista de todo lo acontecido, el presente estudio parte de la hipótesis de que en este proceso penal, la televisión contribuyó a generar un juicio paralelo al margen de los tribunales y la investigación jurídico-policial, ya que desde el primer momento buscó un responsable y una víctima con la clara intención de influir en la opinión pública.

\section{Metodología}

\subsection{Análisis de Contenido}

Para estudiar el fenómeno de los juicios paralelos y el tratamiento mediático del 'caso Bretón' en televisión se ha escogido como metodología el análisis de contenido. Este método permite elaborar un estudio exhaustivo y riguroso acerca del mensaje transmitido por los medios audiovisuales en procesos judiciales mediáticos y mediatizados como el que es objeto de la presente investigación. Asimismo, esta metodología ofrece la posibilidad de comprobar de primera mano el impacto del objeto de estudio, pues la visualización y análisis de las imágenes difundidas en televisión se efectúa sin intervención de terceras personas, lo que dota al estudio de una mayor objetividad.

La muestra seleccionada consta del visionado de treinta y cinco vídeos completos, en los que se examinan las informaciones vertidas sobre el 'caso Bretón' por los magacines matinales La Mañana de la 1 - Televisión Española- y El Programa de $A R$-Telecinco-. El motivo de esta selección radica en que ambos espacios 
televisivos han efectuado un seguimiento amplio y exhaustivo de este suceso. Respeto a la unidad de análisis, se han escogido todos los fragmentos relacionados con el caso, con independencia del género, incluyendo: debates en plató, entrevistas, reportajes y conexiones en directo.

Un factor importante que ha influido a la hora de escoger estos dos programas de televisión es el número de espectadores que poseen. El magacín de Telecinco es líder de audiencia en su franja horaria y La Mañana de la 1, aunque cuenta con un número inferior de telespectadores, es el programa homólogo de la cadena pública ${ }^{4}$. El carácter nacional de Televisión Española (TVE) y Telecinco y el hecho de que ambas cadenas se constituyan como las más representativas del sector público y privado respectivamente han sido otras de las razones que han influido a la hora de seleccionar la muestra.

Al mismo tiempo, que la muestra incluya a una cadena de titularidad pública y otra privada nos va a permitir observar si existe diferencia en el tratamiento de este tipo de sucesos. En otras palabras, se trata de dilucidar si existe divergencia entre la cobertura mediática efectuada por un canal de televisión financiado con fondos públicos, cuyo único objetivo es o debería ser informar, y un canal perteneciente a una empresa privada que, a pesar de afirmar que sus contenidos se rigen por el principio de interés general, el beneficio económico desempeña un papel protagonista en la configuración de su parrilla.

El periodo en el que se tomó la muestra se corresponde con el que abarca la sucesión cronológica de los hechos que integran el 'caso Bretón', centrando el foco de atención en dos momentos concretos: una primera fase que comprende los primeros catorce días de investigación (del 8 al 22 de octubre de 2011), desde la desaparición de los menores -Ruth y José- hasta la detención de su padre -José Bretón-; y un segundo periodo que engloba los tres días iniciales del juicio oral (del 17 al 20 de junio de 2013), en los que declaran en el presunto autor material de los hechos, de la acusación particular y los primeros testigos.

La selección de estos periodos se justifica porque son dos momentos importantes del caso: el inicio y la conclusión. Ambas etapas gozaron de una amplia cobertura mediática y los programas de televisión desplegaron todos sus efectivos para informar con todo detalle de lo acontecido durante los primeros días de investigación (primera fase) y juicio (segunda fase).

\begin{tabular}{|c|c|c|}
\hline $\begin{array}{c}\text { Mes y } \\
\text { año }\end{array}$ & Día & PROGRAMAS \\
\hline
\end{tabular}




\begin{tabular}{|c|c|c|c|c|c|c|c|}
\hline \multirow{9}{*}{ 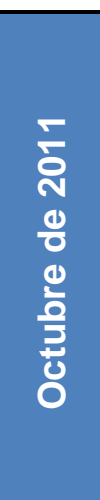 } & \multirow[b]{2}{*}{10} & \multirow{2}{*}{\multicolumn{3}{|c|}{$\frac{\text { El Programa de } A R}{\text { Entrevista }}$}} & \multicolumn{3}{|c|}{ La Mañana de la 1} \\
\hline & & & & & Conexión & Conexión & Entrevista \\
\hline & 11 & \multicolumn{3}{|c|}{ Conexión directo } & Conexión & Conexión & Conexión \\
\hline & 13 & Reportaje & & Entrevista & Reportaje & Conexión & Conexión \\
\hline & 14 & \multicolumn{3}{|c|}{ Entrevista } & \multicolumn{3}{|c|}{ Entrevista } \\
\hline & 18 & \multicolumn{3}{|c|}{ Conexión directo } & \multicolumn{3}{|c|}{ Conexión } \\
\hline & 19 & \multicolumn{3}{|c|}{ Reportaje } & \multicolumn{3}{|c|}{ Entrevista } \\
\hline & 20 & \multicolumn{2}{|l|}{ Reportaje } & Conexión & \multicolumn{3}{|c|}{-} \\
\hline & 21 & \multicolumn{3}{|c|}{-} & \multicolumn{3}{|c|}{ Conexión } \\
\hline \multirow{4}{*}{ 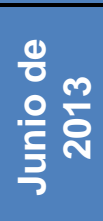 } & 17 & Reportaje & Entrevista & Reportaje & & Debate & \\
\hline & 18 & Debate & Reportaje & Entrevista & & Debate & \\
\hline & 19 & \multicolumn{3}{|c|}{ Reportaje } & \multicolumn{3}{|c|}{ Debate } \\
\hline & 20 & \multicolumn{2}{|l|}{ Reportaje } & Entrevista & \multicolumn{3}{|c|}{ Conexión } \\
\hline
\end{tabular}

Tabla 1. Delimitación de la muestra. Fuente: elaboración propia

Para llevar a cabo el análisis de contenido, se diseñó un protocolo basado en los planteamientos de la bibliografía clásica (Berelson, 1952: 18; Krippendorff, 1990; J. Andréu, 1998) y los postulados del análisis crítico de discurso (Van Dick, 2002). Conforme a estos criterios se configuraron dos bloques principales de análisis: a) Uno de identificación, donde se atendía a la fecha de emisión -fase investigación o juicio-, el programa - La Mañana de la 1 o El Programa de AR-y el formato debates en plató, conexiones en directo, entrevistas o reportajes-; y otro, cuyo eje central era el examen del ámbito, contenidos y enfoques de las diferentes emisiones.

El análisis audiovisual presenta un grado de complejidad mayor que el de un texto impreso, debido a que se han de tener en cuenta un mayor número de elementos (imágenes, entonación, rótulos, sonido y enfoque, entre otros). Por este motivo, se crearon subcategorías específicas en función del formato y se procedió a analizar esencialmente las siguientes cuestiones: (a) el respeto o no de estos formatos por el derecho a la presunción de inocencia de José Bretón; (b) enfoque y narración de los hechos (frame).

Cuando un periodista informa sobre un asunto determinado es prácticamente inevitable que emplee palabras -también denominadas atributos- que sean totalmente objetivas o carentes de tendencias, tonos y matices (Álvarez, 2004: 61). Todos estos atributos de naturaleza subjetiva pueden incidir en la percepción que los espectadores tengan sobre el tema que está siendo tratado. En otras palabras, el 
contexto que los medios otorgan a sus informaciones contribuye a que éstas sean interpretadas por la audiencia de una manera determinada.

A la hora de retransmitir una noticia, los medios de comunicación tienen a seleccionar algún aspecto relevante de la persona o hecho en torno a la que gira la información para hacerlo sobresalir por encima del resto, es lo que Entman denomina frame (Entman, 1993: 52). Relacionado con esto, estaría el framing que hace referencia a "la selección de atributos, valoraciones, opiniones y calificaciones que acompañan a ese primer encuadre -frame-" (Álvarez, 2004: 66).

Teniendo presentes estas consideraciones, se procedió a estudiar el enfoque y tono narrativo de las informaciones. En primer lugar, se puso especial atención al contexto, examinando aspectos como las localizaciones desde donde se informaba, la presencia o no de música de ambientación, las imágenes o vídeos que se emiten mientras hablan los reporteros -planos recurso-, entre otros. En segundo lugar, el foco de atención se centró en el estilo narrativo o enfoque, que fue analizado y clasificado conforme a los siguientes criterios:

a) Informativo neutro: primacía del tono objetivo y los argumentos racionales.

b) Informativo sensacionalista: tono objetivo y predominio de los sentimientos por encima de la razón.

c) Opinativo neutro: tono subjetivo y primacía de los argumentos racionales.

d) Opinativo sensacionalista: tono subjetivo y predominio de la emoción por encima de los argumentos racionales.

Dichos enfoques se aplicaron por analogía también a los rótulos, para de este modo comprobar qué tono primaba en este terreno y, en su caso, establecer una comparativa entre la información de carácter oral y la escrita.

\section{3.- Resultados}

\subsection{Cobertura mediática}

Existen determinados temas que son considerados por los medios de comunicación como más relevantes y a ellos dedican una amplia cobertura y seguimiento. El 'caso Bretón' fue uno de estos asuntos. La televisión empleó buena parte de sus recursos la cobertura del mismo. Los enviados especiales, los reportajes, los debates en plató o las continuas conexiones en directos son algunos de los indicios que nos llevan a afirmar el interés puesto en este caso. Tanto La Mañana de la 1 como El Programa de $A R$ realizaron un amplio seguimiento. Durante todo el tiempo que duró el 
proceso, ambos centraron sus contenidos en él, haciendo del 'caso Bretón' su mayor pilar. Cada información nueva o una última hora al respecto tenía preferencia sobre cualquier otro hecho que estuviese aconteciendo en ese momento.

El arsenal de medios desplegados se hizo más patente en las conexiones en directo, realizadas desde varias localizaciones: juzgados y comisaría de Córdoba, finca de Las Quemadillas, parque en el que supuestamente habían desaparecido Ruth y José, residencia de Ruth Ortiz en Huelva o desde la vivienda de José Bretón en Córdoba. En todos estos lugares, la presencia de cámaras de televisión fue una constante a lo largo de todo el proceso.

Otro aspecto destacable es la persona encargada de realizar las conexiones en directo. Mientras en La Mañana de la 1 fue siempre la misma reportera, o al menos en todo momento una persona ajena al día a día del plató; en El Programa de $A R$ hubo un cambio significativo, a partir del momento en el que el suceso comienza a adquirir una mayor relevancia social, provocada eso sí por los propios medios de comunicación. El magacín de Telecinco decidió enviar como reportero a Nacho Abad, uno de los pesos pesados del programa. Él fue el encargado de informar desde el lugar del suceso de todo aquello que tuviese relación con el 'caso Bretón'. Esto no sería relevante si Nacho Abad realizase las funciones de reportero desde el primer momento, pero no fue hasta después de la detención de José Bretón cuando se incorporó a la corresponsalía.

Si nos trasladamos ahora a los platós de los programas, podemos observar otro ejemplo de esta amplia cobertura, escenificado en esta ocasión en forma de debate. Su empleo y duración iban aumentando a medida que se iban conociendo más datos sobre el proceso, llegando a su punto más álgido en el momento del juicio. En este punto, las tertulias han alcanzado incluso la hora y media de duración.

Las horas de programación dedicadas al 'caso Bretón' no son acordes a los factores noticiosos que reúne este suceso. Es cierto que tuvo continuidad a lo largo del tiempo y que por sus propias características -error del forense a la hora de analizar la procedencia de los huesos, padre que asesina a sus dos hijos pero participa en el proceso de búsqueda- puede fomentar un interés en el público mayor que otros similares, pero este no es motivo de justificación para que se le dediquen tantos minutos de la parrilla televisiva ni para que cada hecho o nuevo descubrimiento del caso sea analizado milimétricamente. Este punto, cuanto menos invita a la reflexión, a cuestionarse dónde se halla realmente el valor noticia del caso y si es este carácter extraordinario el que justifica tan amplio seguimiento. No obstante, es un asunto en el que no vamos a ahondar aquí por desviarse del objeto del presente 
estudio, pero que hemos querido señalar por considerarlo de interés para futuras investigaciones.

Los medios de comunicación analizados han hecho de la desaparición de Ruth y José, y la posterior condena por asesinato con alevosía de José Bretón, un suceso mediatizado y amarillista. Con ello se buscó crear la polémica necesaria para atrapar a la audiencia mediante contenidos audiovisuales con un alto grado de sensacionalismo y opinión desde el primer día.

\subsection{Tratamiento diferenciado de los progenitores}

Para que una noticia sobre un asunto judicial no falte a la verdad y sea respetuosa con la presunción de inocencia deberá hacer alusión a las dos caras de la verdad, es decir, deberá surgir de la confrontación de las imputaciones, declaraciones y alegaciones tanto de la defensa como de la acusación (Barrero, 2001: 182). De modo que la emisión sistemática de una sola de las caras, normalmente la más desfavorable para el imputado, no puede considerarse como información que cumpla el requisito de veracidad informativa.

Desde un primer momento todas las sospechas recayeron sobre la figura de José Bretón, incluso en las dos primeras semanas del proceso donde el padre de los niños aún no había sido detenido. El tratamiento hacia su persona no fue en ningún caso igualitario al de Ruth Ortiz, a quien no se le atribuyó culpabilidad alguna ni jamás recayó sobre ella la más mínima sospecha. Ruth tampoco fue objeto del análisis exhaustivo al que sí se vio sometido José Bretón, estudiado hasta el más mínimo detalle en cada una de sus apariciones públicas. A modo de ejemplo, cabe citar el reportaje emitido el 17 de junio de 2013 por El Programa de $A R$ en el que se declara lo siguiente:

"Se siente el centro de atención. Tiene los pies abiertos, manos esposadas, gafas colgadas del cuello, lleva calcetines."

El análisis pormenorizado de la figura de José Bretón se acentuó en los días en los que se celebró el juicio, cuando las imágenes de sus respectivas declaraciones en sala se hicieron públicas. A través de ellas, se estudió punto por punto el comportamiento de Bretón en sede judicial:

"Este tipo de personas que son narcisistas, manipuladoras, etc., cuando les falta ese «aquí ordeno yo y mando yo», cuando les falta ese 
machismo interior, lo que hacen es pedir ayuda por lástima" (Vídeo de La Mañana de La 1 de 19 de junio de 2013).

Sin embargo, la descomposición detalle por detalle de la vida de José Bretón ya llevaba realizándose desde su detención. Las referencias a su pasado militar, sus problemas psicológicos, su crisis conyugal con Ruth Ortiz o su aspecto físico fueron una constante:

"Escrupuloso, con complejo de inferioridad machista, maniático y obsesivo. Así es José Bretón, que a lo largo de los diez años fue desarrollando sus manías y su carácter autoritario, obsesivo y manipulador" (Reportaje de El Programa de AR de 19 de junio de 2013).

Los antecedentes psiquiátricos han sido, desde el primer momento, uno de los aspectos más recurrentes para hacer hincapié en la culpabilidad de José Bretón, mencionados tanto en los debates en plató, como en los reportajes e incluso en las conexiones en directo:

"El padre de los pequeños a raíz de la separación conyugal estaba necesitando ayuda psiquiátrica, y esa ayuda psiquiátrica ya la había requerido también en los años 90 a raíz de otra ruptura sentimental anterior a este matrimonio" (Conexión en directo en La Mañana de La 1 del 11 de octubre de 2011).

Estos antecedentes en cuanto a sus problemas psicológicos se vieron ligados no solo a sus relaciones sentimentales, sino también a su pasado militar en la Guerra de los Balcanes, donde estuvo tres años en Bosnia como soldado. Los reporteros en su afán por sacar a la luz datos de su pasado, entrevistaron a las personas cercanas a la residencia de Bretón y otorgaron especial importancia a los testimonios de sus vecinos:

"Creo que sí que es militar, que ha estado en Bosnia, osea que se ve un tío preparado y quizá por eso no se derrumba" (Declaración de un vecino de José Bretón integrada en el reportaje de El Programa de AR de 20 de octubre de 2011).

Pero quizá las diferencias más significativas se observaron cuando el magacín de Telecinco emitió un reportaje sobre la vida en pareja de ambos. En él se ensalza la 
personalidad de Ruth y se devalúa y somete a continuas denigraciones a José Bretón:

"Ella es licenciada en veterinaria y se encarga de llevar el dinero a casa.

Él es ex militar, no acabó sus estudios en Derecho y está parado."

(Reportaje de El Programa de AR de 19 de junio de 2013).

También se ha podido advertir esta diferenciación entre progenitores en el ámbito de las entrevistas. Éstas se han realizado en su mayoría al entorno de la madre, dejando a los familiares de Bretón excluidos a la hora de aportar sus puntos de vista acerca de lo ocurrido. Tan sólo se recurrió al entorno paterno en un par de ocasiones concretas: en primer lugar, para recoger las declaraciones de una amiga de José Bretón que no aportan en sí nada relevante al caso, sino que simplemente aluden al comportamiento de los niños en el día a día. En segundo lugar, para intentar entrevistar a la madre de José Bretón, quien prácticamente se niega a contestar y trata de evitar a la prensa.

La representación de Ruth Ortiz, por el contrario, apenas ha estado ligada a ningún acontecimiento de su pasado y en las pocas ocasiones que sí se ha hecho referencia ha sido de manera positiva. Desde un primer momento, en ese empeño por buscar un culpable y una víctima, se la ha situado como la parte perjudicada, enfocando las entrevistas hacia un terreno más sentimental que puramente informativo con preguntas del tipo “¿cómo lo está llevando Ruth?” o “¿cómo van los ánimos?".

El siguiente gráfico muestra el número de vídeos que aluden a la historia o pasado de los progenitores y la forma en la que lo hacen. En él se puede observar como ninguno de ellos recurre a la historia de José Bretón para destacar algún aspecto positivo de su persona. Algo que no ocurre en el caso de Ruth, en el que o bien no se indaga en su pasado o, si se hace, es para alagarla.

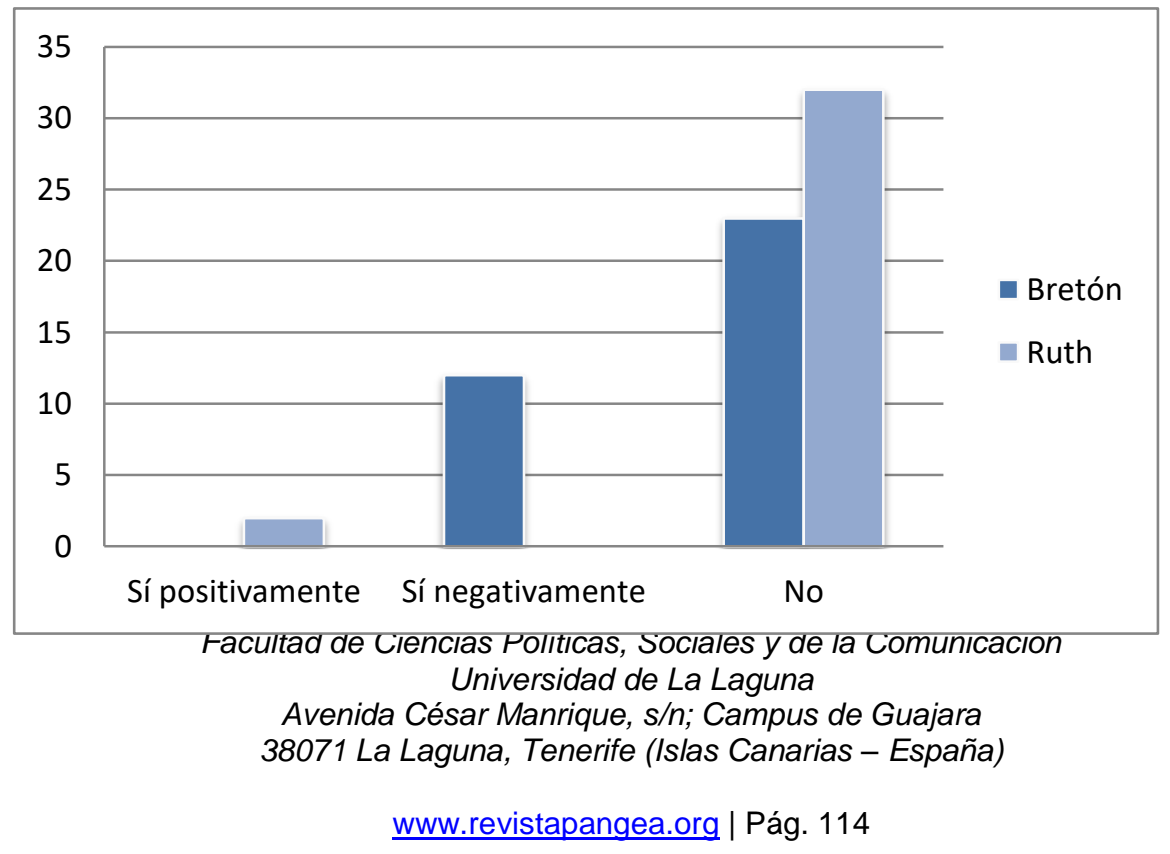




\section{Gráfico 1. Referencia a la historia de los progenitores. Fuente: elaboración propia}

Estas diferencias entre progenitores también han sido perceptibles en las imágenes mostradas en televisión, ya sea bien a través de los vídeos, donde esta diferenciación se ha visto acompañada de las voces en off, o en las fotos que se iban mostrando para acompañar los testimonios de los colaboradores en plató o de las conexiones en directo. En gran parte ellas, José Bretón aparece retratado de una manera seria y fría, mientras que a Ruth Ortiz se la representa como una persona afectada que está pasando por un mal momento.

\subsection{Predominio del enfoque sensacionalista}

Aquí se ha procedido a examinar el contexto y tono narrativo de los mensajes audiovisuales que conforman la muestra. Se ha detectado que tanto El Programa de $A R$ (Telecinco) y La Mañana de la 1 (TVE) han llevado a cabo una cobertura del caso, en la que prevalece el enfoque sensacionalista por encima del tono informativo neutro. Los sentimientos y la emoción se anteponen a los argumentos racionales en la mayoría de las informaciones relacionadas con este caso. El $61,76 \%$ de las conexiones en directo utiliza sensacionalismo, frente a un $30,76 \%$ que apuesta por el estilo neutro.

Estas cifras son mucho más llamativas en géneros interpretativos como el reportaje. En el $55 \%$ de ellos predomina la opinión y el sensacionalismo. Un dato muy significativo a este respecto, es que en este género parece no haber cabida para la mera información, ya que en ninguno de los reportajes sometidos a examen se ha detectado un tono informativo neutro.

El siguiente gráfico muestra el enfoque empleado en un total de 22 vídeos, en los que 13 son conexiones en directo y los 9 restantes son reportajes. En él se puede apreciar una clara tendencia al enfoque sensacionalista, especialmente acentuada en el caso de los reportajes. Es aquí donde la mera información u opinión neutral, basada en argumentos racionales, deja vía libre a la emoción, los sentimientos y a la especulación. 


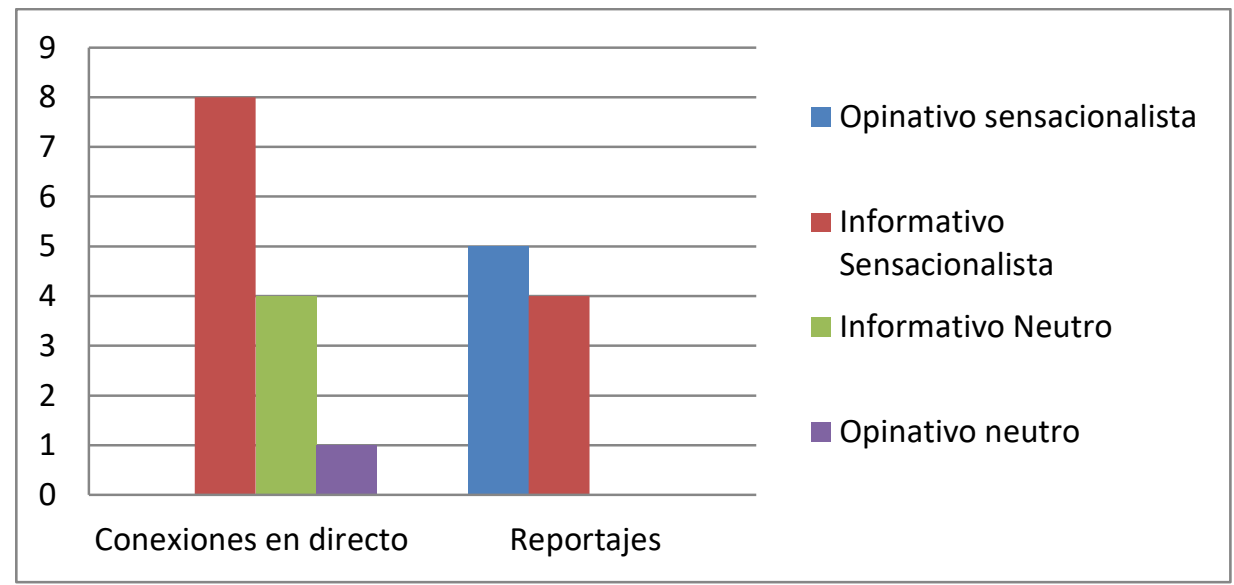

Grafico 2. Enfoque. Fuente: Elaboración propia

El sensacionalismo o amarillismo se define como la tendencia a presentar los hechos y las noticias de modo que produzcan emoción o impresión (Berti, 2010: 43). En este sentido, se entiende que hay presencia de amarillismo cuando los periodistas en sus informaciones al respecto del 'caso Bretón' emplean adjetivos calificativos, tienden a la exageración o apelan continuamente a los sentimientos. En la siguiente tabla se exponen una serie de ejemplos que vienen a mostrar el tono sensacionalista utilizado en estos programas.

\begin{tabular}{|c|c|c|c|}
\hline Programa & Fecha & Ejemplo & Formato \\
\hline \multirow{3}{*}{ 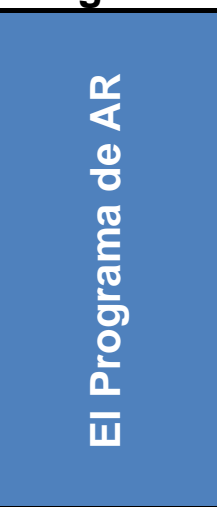 } & $11 / 10 / 2011$ & $\begin{array}{l}\text { En referencia a la familia materna: } \\
\text { "Estuvieron todo el día entrando y saliendo } \\
\text { de comisaría. Ellos están muy abatidos, } \\
\text { muy angustiados porque las noticias no } \\
\text { son nada halagüeñas. Y la verdad es que } \\
\text { están muy deprimidos..... }\end{array}$ & $\begin{array}{l}\text { Conexión } \\
\text { en directo }\end{array}$ \\
\hline & $18 / 06 / 2013$ & $\begin{array}{l}\text { "Fíjense en el imán de la nevera con una } \\
\text { foto de la pequeña Ruth". }\end{array}$ & Reportaje \\
\hline & 20/06/2013 & $\begin{array}{l}\text { "Pepa -directora de la guardería- nos } \\
\text { enseña el gran vacío que ha dejado aquí } \\
\text { la enorme sonrisa del pequeño José". }\end{array}$ & Reportaje \\
\hline \multirow{3}{*}{ 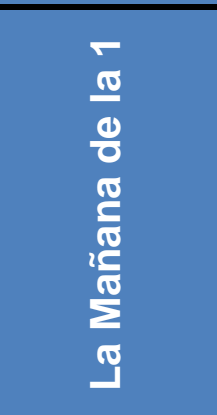 } & $13 / 11 / 2011$ & $\begin{array}{l}\text { En referencia a Ruth Ortiz: "[...] aunque } \\
\text { normalmente se le habilita una sala } \\
\text { especial y está asistida por un psicólogo, } \\
\text { estar allí -en comisaría- le resulta algo } \\
\text { incómodo y angustioso". }\end{array}$ & $\begin{array}{l}\text { Conexión } \\
\text { en directo }\end{array}$ \\
\hline & $13 / 11 / 2011$ & "Ha debido ser un mazazo para la madre" & $\begin{array}{l}\text { Conexión } \\
\text { en directo }\end{array}$ \\
\hline & $18 / 11 / 2011$ & $\begin{array}{l}\text { Información sobre la declaración en juicio } \\
\text { de la directora de la guardería de José: }\end{array}$ & $\begin{array}{l}\text { Conexión } \\
\text { en directo }\end{array}$ \\
\hline
\end{tabular}




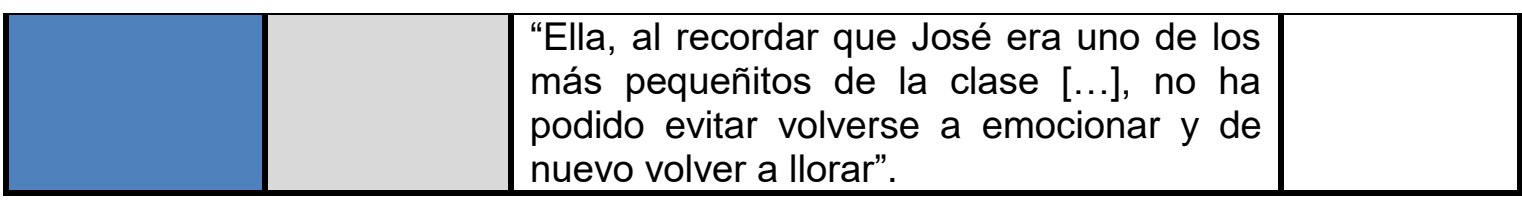

Tabla 2. Ejemplos de enfoque sensacionalista. Fuente: elaboración propia

Se puede comprobar, de este modo, como en la narración de los hechos abundan adjetivos, en ocasiones precedidos por el cuantificador muy, que se utiliza en español para construir el grado superlativo (p.ej. muy abatiditos, muy angustiados). Asimismo, se advierte un alto grado de contenido emocional en los mensajes. Elementos, todos ellos, que pueden influir en la manera en que la audiencia percibe este caso y que contribuyen a banalizar la información.

Otro dato relevante y que ha llamado la atención, es el estilo utilizado en los rótulos. Éstos, al contrario que en el caso anterior, tienden a mantener tono informativo neutro. Tanto es así, que de los 40 rótulos sometidos a examen, más de la mitad de ellos $(70 \%)$ utilizan este estilo para sus mensajes. Por su parte, el sensacionalismo está implícito en menos de una tercera parte de ellos (22,5\%). Como ejemplo, se pueden mencionar los siguientes:

1. "La familia permanece en comisaría, tras ser convocada por la policía" (Conexión en directo de La Mañana de la 1 de 10 de octubre de 2011).

2. "El padre ha colaborado en el registro de la finca de sus padres" (Conexión en directo de El Programa de AR de 11 de octubre de 2011).

3. "El padre podría estar en tratamiento psicológico por una ruptura sentimental (Conexión en directo de La Mañana de la 1 de 11 de octubre de 2011).

4. "Detienen al padre de los niños desaparecidos" (Conexión en directo de El Programa de AR de 18 de octubre de 2011).

5. "El padre podría estar en tratamiento psicológico por la ruptura sentimental" (Conexión en directo de La Mañana de la 1 de 11 de octubre de 2011).

Se observa como en los cuatro primeros el tono es objetivo y se limitan a poner de relieve el contenido de las informaciones que está dando el reportero en ese momento. Sin embargo, en el último el estilo cambia. Se introduce el verbo poder, que indica posibilidad, y se procede a enunciar una mera suposición. Además, el contenido de la información ya no tiene nada que ver con la investigación policial, sino que se refiere al estado psicológico de José Bretón. 
En lo que concierne al marco o contexto de las informaciones, se ha verificado que más de la mitad de los reportajes y conexiones en directo (59\%) emplean música de intriga de fondo. Esto es más evidente en El Programa de $A R$, que emplea la música de ambientación en todos y cada uno de sus reportajes y conexiones en directo. La Mañana de la 1, por el contrario, prescinde de la música en sus conexiones, pero se sirve de ella en los reportajes.

\subsection{Derecho a la presunción de inocencia}

El derecho a la presunción de inocencia, consagrado en el artículo 24.2 CE, se proyecta específicamente sobre los procesos judiciales en los que se ventilan causas penales o administrativas (Barrero, 2001: 179). Se trata de un derecho fundamental de toda persona frente al Estado, que impide un pronunciamiento de condena "que no esté fundado en pruebas que, legítimamente obtenidas, se hayan practicado con todas las garantías legalmente exigidas" 5 . De este modo, toda acusación que se realice a un determinado sujeto deberá ir acompañada de una prueba destinada a corroborar aquellos hechos que se le imputan, de tal manera que, en ausencia de aquéllas, el juez o tribunal que conozca del proceso deberá declarar la inocencia del acusado. Igualmente sucederá cuando, una vez practicada la prueba, el juez tenga dudas acerca de lo ocurrido, en este caso el juzgador tendrá que inclinarse por la interpretación más favorable al reo (principio in dubio pro reo).

El derecho la presunción de inocencia no solo se circunscribe a la esfera procesal, sino que como ha reconocido el Tribunal Constitucional en su Sentencia 166/1995 "tiene una dimensión extraprocesal y comprende el derecho a recibir la consideración y el trato de no autor o partícipe en los hechos de carácter delictivos". En este sentido, el único acto que puede quebrantar la presunción de inocencia es la sentencia de condena que declara la autoría del delito. De tal modo, que habrá que desconfiar de aquella información que dé por cierta la culpabilidad de una persona por el mero hecho de verse sometida a una investigación judicial (Barrero, 2001: 181).

En este punto de la investigación, se ha querido averiguar si los programas seleccionados han respetado el derecho a la presunción de inocencia, o por el contrario, consideraron culpable a José Bretón desde el comienzo de la investigación. Mediante el análisis de contenido, se ha comprobado que el $60 \%$ de las emisiones consideran a José Bretón responsable de la desaparición y muerte de sus hijos con carácter previo a la sentencia condenatoria dictada por la Audiencia 
Provincial de Córdoba. Especialmente vulnerables a ello son los debates y los reportajes. En las cuatro tertulias -correspondientes a la fase de juicio oral-, se atribuye a José Bretón la autoria del asesinato de los dos niños. Algunos de los testimonios que merecen ser destacados son los siguientes:

El Catedrático en Psicólogía, Pedro Hernández-Guanir, se justifica, dando a entender que el hecho de que que no califique a Bretón como psicópata no implica que le esté defendiendo o exculpando:

"(Bretón) no es un psicópata, pero cuidado porque, al decir que no es un psicópata parece que le estás disculpando, diciendo que es una persona sana y buena" (Pedro Hernández-Guanir, debate de La Mañana de la 1 de 17 de junio de 2013).

Por su parte, el Catedrático en Derecho de la Información, Teodoro González Ballesteros, dá por ciertos unos hechos -el doble asesinato de los niños- , que aún están pendientes de ser probados en sede judical y cuya autoría aún no está decretada por el Tribunal:

"Yo creo que una persona que hace lo que José Bretón ha hecho, no es una persona normal" (Teodoro González Ballesteros, debate de La Mañana de la 1 de 17 de junio de 2013).

El 18 de junio de 2013, José Bretón declara en juicio como acusado y niega que fuera él el responsable de quemar y matar a sus hijos. Asimismo, procede a dar su versión de los hechos alegando que, mientras los niños dormían en el coche, él quemó basura, papeles y ropa en la hoguera que encendió en 'Las Quemadillas'. Sobre este asunto se debate en el plató de TVE y la periodista, Victoria Lafora, dá su opinión al respecto.

"Él (Bretón) habla de los niños en presente y no se equivoca ni una sóla vez, todo el rato habla de sus hijos como que están vivos, es dicir, está perfectamente planificada la estrategia" (Victoria Lafora, debate de La Mañana de la 1 de 18 de junio de 2013).

Otro de los aspectos relevantes en lo que corncierne a las tertulias en plató, es el papel que desempeñan las conductoras de ambos programas. En la totalidad de los debates analizados (4), las presentadoras se hacen partícipes e intervienen aportando sus opiniones o puntos de vista al respecto:

José Bretón declara en juicio y la presentadora de Telecinco comenta: "Durante cinco minutos no mueve un músculo, prácticamente no 
pestañea. Esto nos ha impresinado. Parece que es una persona que no está en el mismo escenario que las demás" (Ana Rosa Quintana, debate de El Programa de $A R$ de 18 de junio de 2013).

"Dice el abogado que va a contestar a todo, pero se va a controlar mucho en lo que diga para no meter la pata" - en referencia a José Bretón. (Mariló Montero, debate de La Mañana de la 1 de 17 de junio de 2013).

Los reportajes -todos ellos centrados en la figura de Bretón- también son muy propensos a vulnerar el derecho a la presunción de inocencia. De hecho, el 88\% de ellos tienen a atribuirle responsabilidad penal. En este formato, se somete al imputado a toda clase de valoraciones y análisis acerca de su aspecto físico, su pasado como exmilitar en Bosnia, su relación con Ruth o su papel como padre.

En la presente investigación, se ha comprobado que el $40 \%$ de los vídeos no atribuyen responsabilidad criminal a José Bretón, frente a un $60 \%$ que sí lo consideran culpable. Dentro de este último porcentaje, un 34\% fundamentan la acusación en un conjunto de aspectos destacados de la vida y forma de ser de José Bretón (categoría multirespuesta Otros): su carácter, su pasado como militar, sus declaraciones ante la policía, etc; mientras que $9 \%$ se refugian exclusivante en las declaraciones de José Bretón durante todo el proceso judicial para considerarle autor material de los hechos.

Por su parte, $8 \%$ lo considera culpable atendiendo a su estado psicológico. En este sentido, se suele alegar que Bretón es un hombre "alterado emocionalmente" y que "se encontraba recibiendo atención psicológica tras su separación con Ruth Ortiz". En el gráfico que se expone a continuación, se pueden apreciar estos y otros motivos, así como el porcentaje de emisiones que han respetado la presunción de inocencia (un $40 \%$ frente a un $60 \%$ que no lo ha hecho). 


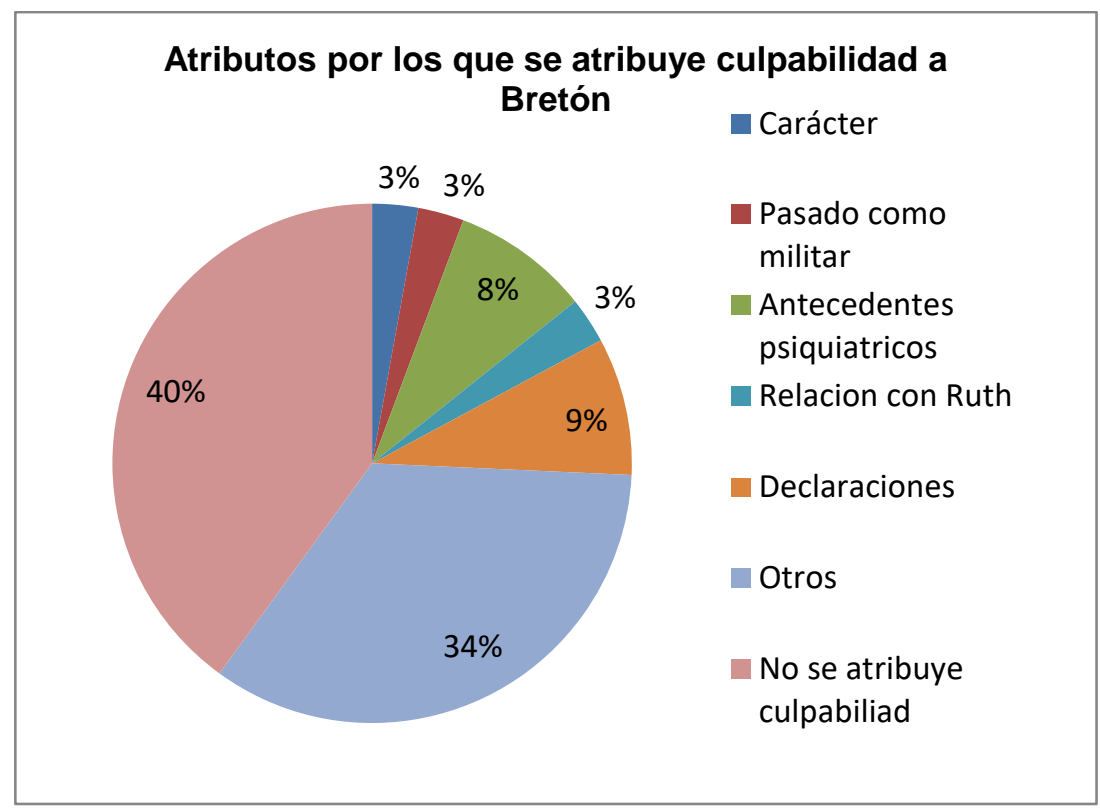

Gráfico 3. Atributos por los que se atribuye culpabilidad a Bretón. Fuente: elaboración propia

\subsection{Diferencias entre la cobertura de la televisión pública y privada}

Uno de los objetivos que se planteaban con la presente investigación era dilucidar si existe un tratamiento dispar del caso por parte de la televisión pública y la privada. Entendiendo que la primera, en tanto que servicio público, se circunscribe a la satisfacción del interés general y, por ende, su finalidad es o debería ser meramente informativa. La televisión privada, por su parte, aunque aduce amparase en el interés general a la hora de configurar sus informaciones, es evidente que el componente económico desempeña un papel fundamental en este terreno.

Tras el análisis detallado de la muestra, se ha llegado a la conclusión de que la cadena pública (TVE) fue más algo más cauta a la hora de cubrir el caso Bretón y preservó más el derecho a la presunción de inocencia del protagonista. No obstante, las cifras tampoco son demasiado alentadoras. En una comparativa de ambos matinales, se percibe como el matinal de Telecinco transgrede este derecho con más frecuencia (en 12 de los 18 vídeos) que el de la cadena pública (9 de los 17 vídeos). 


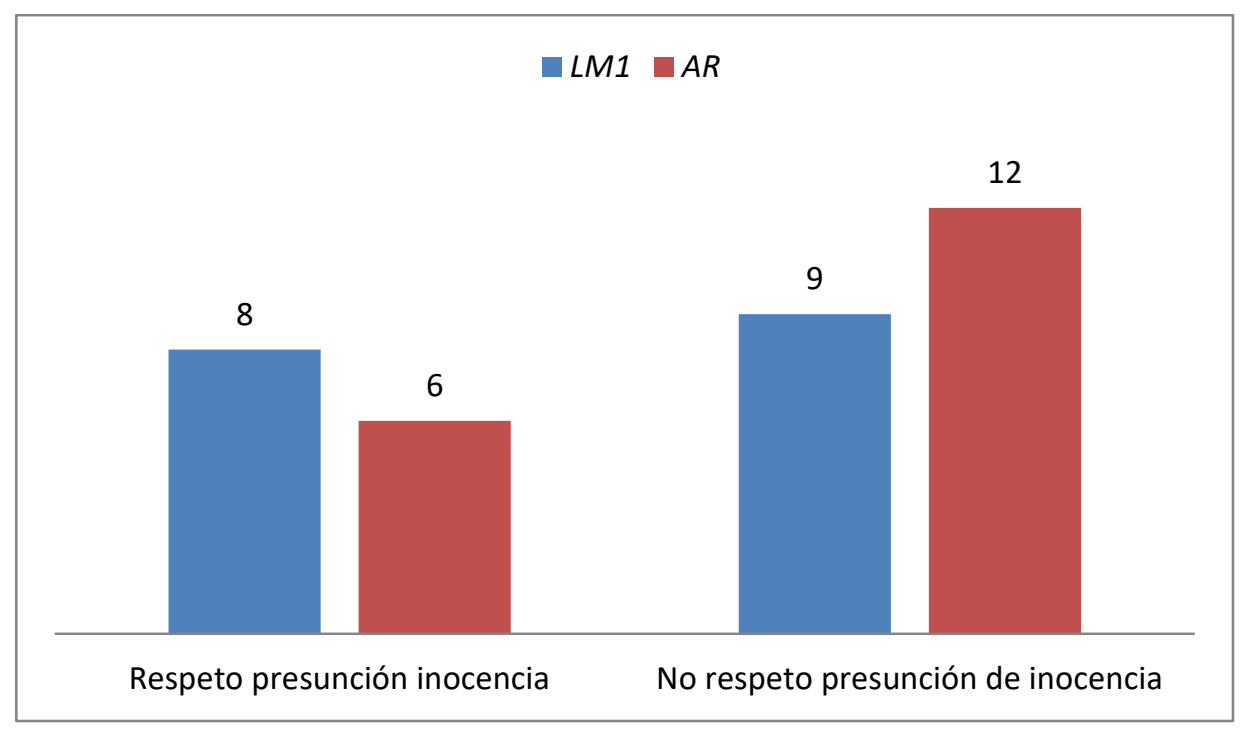

Grafico 4. Presunción de inocencia: comparativa por programas. Fuente: elaboración propia

Se ha comprobado, asimismo, que en la cobertura de la fase de instrucción, la televisión púbica se muestra más neutral y evita especular acerca de lo ocurrido. Es frecuente que en sus conexiones en directo los reporteros hagan hincapié en que "los datos aún son confusos", "no hay nada claro", "no hay ningún detenido y se debe respetar la presunción de inocencia". De hecho, no se informa de que la policía venía considerando a José Bretón como principal sospechoso de la desaparición de sus hijos, hasta el momento de la detención el día 18 de octubre de 2011. Algo que no ocurre en El Programa de $A R$, donde desde el día 13 de octubre se empieza a especular con la posibilidad de que sea el padre el responsable. Sin embargo, esta tendencia se difumina en la segunda fase de juicio oral, momento en el que ambos magacines no dudan en afirmar la culpabilidad del progenitor con carácter previo a la resolución judicial.

\subsection{Falta de rigor en el empleo de términos jurídicos}

La cobertura de los procedimientos judiciales exige una preparación específica del profesional. El informador judicial debe ser capaz de comprender la compleja y específica terminología jurídica y adaptar esos conceptos a un lenguaje comprensible para el gran público. Asimismo, ha de tener unas nociones jurídicas básicas para que la calidad y veracidad de sus informaciones no se vea menoscabada. Entre estos conocimientos, los principales serían: la distinción de las 
distintas fases del procedimiento judicial y la diferencia existente entre un acusado, procesado, imputado y condenado.

En la cobertura televisiva del 'caso Bretón', se ha comprobado que existen deficiencias en el manejo de términos jurídicos:

a) Se desconoce la diferencia entre homicidio y asesinato, y con frecuencia se intercambian o se emplean estos términos como sinónimos.

b) Se alega que José Bretón es detenido por la policía por "un presunto delito de desaparición forzosa" (Reportaje de El Programa de AR de 19 de octubre de 2011). Un delito, que no existe en el Código Penal (CP) español, y al que probablemente aludieron para referirse al delito de detenciones ilegales, tipificado en nuestro ordenamiento jurídico [art. 163 CP].

c) Confusión a la hora de enunciar los motivos de la detención. Cuando el 18 de octubre de 2011 José Bretón es detenido, estos programas se hacen eco de la noticia y unos alegan que es sospechoso de la comisión de un delito de homicidio, otros de asesinato y los más cautelosos le atribuyen el delito de detención ilegal o el de secuestro de los menores.

La realidad es que la policía detiene a Bretón por las contradicciones en las que incurre en la narración de los hechos. Tras pasar a disposición judicial, el magistrado ve indicios razonables de criminalidad y dicta auto de prisión provisional comunicada y sin fianza por los delitos de detención ilegal cualificada por desaparición de menores y simulación de delito ${ }^{6}$. No será hasta el auto de procesamiento de 15 de febrero de 2013, cuando el juez le impute los dos delitos de asesinato con alevosía y un tercero de denuncia falsa.

\section{4.- Conclusiones}

La presente investigación ha tenido como objetivo analizar el fenómeno de los juicios paralelos mediante la cobertura televisiva del 'caso José Bretón'. Se partía de la hipótesis de que la televisión contribuyó a generar un juicio paralelo al margen de los tribunales y la investigación jurídico-policial, ya que desde el primer momento buscó un responsable (José Bretón) y una víctima (Ruth Ortiz) con la clara intención de influir en la opinión pública. A la luz de los datos obtenidos a lo largo de la investigación se confirma la hipótesis, concluyendo que: 
Se observan juicios paralelos en la mayoría de los vídeos analizados. El tratamiento que la programación española otorga al 'caso Bretón', sometiéndolo a toda clase de valoraciones y formulando diversas hipótesis sobre lo ocurrido, contribuye a generar en la audiencia una opinión determinada, normalmente negativa, sobre la persona que en un futuro será enjuiciada.

Vulneración del derecho a la presunción de inocencia: más de la mitad de los vídeos analizados incurren en quebrantamiento de este derecho fundamental.

Tratamiento diferenciado de los progenitores. Los medios tienden a atribuir los roles de culpable (padre) y víctima (madre). Esto se manifiesta sobre todo en las entrevistas, que se centran mayoritariamente en la familia materna, y en el enfoque de los reportajes, en los que se somete a la figura de José Bretón a todo tipo de valoraciones y análisis.

Tendencia al enfoque sensacionalista: continua apelación a los sentimientos, por encima de la razón, suposiciones, frecuente uso de adjetivos calificativos y tendencia a la exageración. Asimismo, es habitual la aparición de juicios de valor infundados, que se hace más evidente en los reportajes (tono narrativo, música de ambientación, empleo de adjetivos en grado superlativo...), especialmente en la fase del juicio oral.

Continuas faltas de precisión a la hora de emplear términos jurídicos: confusión de conceptos (asesinato y homicidio) y alusión a delitos que no existen (desaparición forzosa).

Esta investigación, que aborda un tema novedoso y sobre el que existe poca bibliografía al respecto (Caso Aitana: Macía y Galván 2012: 366; Niñas de Alcásser: Arnau, 1998), ha puesto de relieve la falta de rigor informativo de la programación matinal española a la hora de tratar asuntos tan delicados como los judiciales. Asimismo, invita a la reflexión acerca de la conveniencia de que tanto las cadenas públicas como las privadas traten con el máximo respeto y cautela los temas judiciales, evitando que las informaciones que se viertan en sus programas fomenten la celebración de juicios paralelos o infrinjan los derechos fundamentales como el derecho a la presunción de inocencia de la persona/s implicada/s en el caso. 


\section{6.- Bibliografía}

ÁLVAREZ LÓPEZ, I. (2004): Los usos estratégicos del framing (la campaña electoral municipal de Madrid 2003), Madrid, Universidad Complutense de Madrid, pp. 5171. En línea: http://biblioteca.ucm.es/tesis/inf/ucm-t28102.pdf [Consultado 04/03/2015].

ANDREU ABELA, J. (2002): Las técnicas de Análisis de Contenido: Una revisión actualizada, Fundación Centro de Estudios Andaluces, Sevilla.

BARRERO ORTEGA, A. (2002): “Juicios paralelos y Constitución: su relación con el Periodismo", en Revista Internacional de Comunicación, oㅡ 6, pp. 171-189. En línea: http://dialnet.unirioja.es/servlet/articulo?codigo $=961843$ [Consultado 15/02/2015].

BERTI, F. (2010): "Sensacionalismo y amarillismo en los medios de comunicación", en Ensayos Contemporáneos, Buenos Aires, Vol. 32, pp. 43-45. En línea: http://fido.palermo.edu/servicios dyc/publicacionesdc/archivos/163 libro.pdf [Consultado 15/02/2015].

BUSTAMANTE, E (1999): La televisión económica: financiación, estrategias y mercados, Barcelona, Gedisa.

ENTMAN, R. M. (1993): "Framing: Towards Clarification of Fractured Paradimg", en Journal of Communication 43 (4), pp. 51-58. En línea: http://sotomove.geo.uzh.ch/sotomo/pps/lit/entman 93.pdf [Consultado 20/04/2015].

GARCÍA AVILÉS, J.A (2007): "El infoentretenimiento en los informativos líderes de audiencia en la Unión Europea”, en Anàlisi: Quaderns de comunicació i cultura, ํㅡ 35, pp. 47-63. En línea: http://www.analisi.cat/index.php/analisi [Consultado 11/05/2015].

JUANES PECES, A. (2007): "Los juicios paralelos. El derecho a un proceso justo. Doctrina jurisprudencial en relación con esta materia", en VV.AA (2007): Justicia y medios de comunicación. Cuadernos de Derecho Judicial no XVI, Madrid, CGPJ.

LANGER, J. (1998). Tabloid Television: popular journalism and the "other news», Londres y Nueva York, Routledge.

MACIÁ BARBER, C. y GALVÁN ARIAS, Ma . A (2012): "Presunción de inocencia y deontología periodística: el caso Aitana", en Revista Latina de Comunicación Social, $\quad \mathrm{n}^{\circ} 67.6 \mathrm{En}$ línea: http://www.revistalatinacs.org/067/art/960 Getafe/16 Macia.html [Consultado 15/02/2015].

ORENES RUÍZ, J.C. (2014): "El control no jurisdiccional de los juicios en televisión por parte de las autoridades audiovisuales", en Dilemata, no 14, pp. 121-140. En 
línea: http://dialnet.unirioja.es/servlet/articulo?codigo=4780375 [Consultado el 10/02/2015].

THOMAS, B. (1990): Finding Truth in the Age of «Infotaiment», Washington D.C, Research Reports.

RODRÍGUEZ FERNÁNDEZ, R. (2012): "Los juicios paralelos", en Diario la Ley, oo 7802 de 21 de febrero, pp. 1-25.

SPARKS, C.; TULLOCH J. (ed.). (2000). Tabloid Tales: Global Debates over Media Standards, Nueva York y Oxford, Rowman and Littlefield.

VAN DICK (1999): "Análisis crítico del discurso y el pensamiento social", en Athenea Digital. Revista de Pensamiento e Investigación Social, Barcelona, pp. 18-24.

\section{NOTAS}

[1] Sentencia del Tribunal Constitucional 30/1982, de 1 de junio. Ref. Aranzadi RTC 1982130.

[2] Auto de Prisión Provisional del Juzgado de Instrucción no 6 de Córdoba de 20 de octubre de 2011.

[3] Sentencia de la Audiencia Provincial de Córdoba Sección Tercera rollo del Tribunal de Jurado 1/2013, de 22 de julio.

[4] Fuente: Kantar Media Informes de audiencias de octubre de 2011 y junio 2013.

[5] Sentencia del Tribunal Constitucional núm. 166/1995 de 20 noviembre. Ref. Aranzadi RTC1995\166.

[6] Auto de Prisión Provisional del Juzgado de Instrucción no 6 de Córdoba de 20 de octubre de 2011.

\section{Forma de citar este artículo en bibliografías}

SÁNCHEZ MONCADA, María y VEIGA FRANCO, María (2015): "Los juicios paralelos en el proceso penal: tratamiento mediático del 'caso bretón", en Revista PANGEA, 6, páginas 103 a 126. Red Académica Iberoamericana de Comunicación. Recuperado el de de 2 de: http://www.revistapangea.org 